\title{
Simultaneous Fractures of the Ipsilateral Scaphoid and Distal Radius
}

\author{
Timothy P. Fowler, MD ${ }^{1} \quad$ Elizabeth Fitzpatrick, $\mathrm{MD}^{1}$ \\ 1 Department of Orthopaedics and Rehabilitation, \\ University of lowa Hospitals and Clinics, lowa City, lowa \\ J Wrist Surg 2018;7:303-311. \\ Address for correspondence Timothy P. Fowler, MD, Department of \\ Orthopaedics and Rehabilitation, University of lowa Hospitals and \\ Clinics, 200 Hawkins Drive, lowa City, IA 52242-1009 \\ (e-mail: timothy-fowler@uiowa.edu).
}

\begin{abstract}
Keywords

- distal radius fractures

- scaphoid fractures

- ipsilateral fractures

Background Ipsilateral fractures of the distal radius and scaphoid are rare, with few reports describing mechanisms of injury, fracture patterns, and treatment approaches. Purpose This article describes the clinical and radiographic features of ipsilateral distal radius and scaphoid fractures occurring simultaneously.

Materials and Methods Electronic databases from 2007 to 2017 at a single Level 1 trauma center were reviewed for patients with concurrent fractures of the distal radius and scaphoid. Patient demographics, injury mechanism, scaphoid and distal radius fracture pattern, treatment approach, and radiographic healing were studied.

Results Twenty-three patients were identified. Nineteen of the $23(83 \%)$ were males, and 19 of 23 (83\%) of the injury mechanisms were considered high energy. Twenty-two of the 23 (96\%) scaphoid fractures were nondisplaced, all treated with screw fixation. Most distal radius fractures were displaced and comminuted, 17 of 23 (74\%) were intraarticular. All distal radius fractures were treated surgically with internal and/or external fixation. Three patients were lost to follow-up. Average follow-up of the remaining 20 was to 19.8 weeks. Nineteen of the 20 (95\%) scaphoids healed, one scaphoid went on to nonunion with avascular necrosis. All 20 radius fractures healed, 16 of 20 (80\%) in anatomic alignment.

Conclusion Ipsilateral fractures of the distal radius and scaphoid are rare and are usually result of high-energy mechanisms. The scaphoid fracture is usually a nondisplaced fracture at the waist. The distal radius fracture pattern varies but most are displaced and comminuted. The union rate of the scaphoid is high, even if subjected to radiocarpal distraction required for distal radius management.

Level of Evidence Therapeutic level IV study.
\end{abstract}

Simultaneous fractures of the ipsilateral scaphoid and distal radius are rare. The relatively few published reports on this injury combination demonstrate varying patient demographics, injury mechanisms, and modes of treatment. ${ }^{1-13}$ Classification schemes and treatment methods for both fractures have evolved during this time period, most notably influenced by the introduction of volar locking plates for distal radius fractures in $2002 .{ }^{14}$ Minimally displaced scaphoid fractures treated with screw fixation may increase

received

October 6, 2017

accepted after revision

March 6, 2018

published online

April 10, 2018 rates of, and decrease time to, fracture healing resulting in shorter convalescence, ${ }^{15-17}$ although this remains a subject of debate. ${ }^{18-20}$

Simultaneous fractures may necessitate use of competing forms of fracture stabilization, since traction is usually applied to reduce distal radius fractures and scaphoids are compressed. Some have expressed concern over displacing a fractured scaphoid when reducing a distal radius or using distal radius external fixation. ${ }^{5,6}$
Copyright $\odot 2018$ by Thieme Medical Publishers, Inc., 333 Seventh Avenue, New York, NY 10001, USA. Tel: +1(212) 584-4662.
DOI https://doi.org/ 10.1055/s-0038-1641719. ISSN 2163-3916. 
The purpose of this retrospective study is to describe the simultaneous scaphoid and distal radius fractures that presented to a single Level 1 trauma center since 2007, noting fracture patterns, mechanisms of injury, treatment approach and complications, and radiographic healing rate.

\section{Materials and Methods}

Patients presenting to our institution with acute injuries to the upper limb were eligible for inclusion in this report. Electronic billing databases from 2007 to 2017 were searched to identify patients assigned International Classification of Diseases (ICD) diagnosis codes (813/814 groupings) and/or Current Procedural Terminology (CPT) codes $(25628+25606 / 25607 / 25608 / 25609 / 20690)$ for scaphoid and distal radius fractures occurring on the same encounter. ICD codes were assigned by certified coding specialists based on clinic documentation. CPT codes were assigned by the coders with oversight and approval by the treating physician. Patients with simultaneous fractures of both bones to the ipsilateral limb were identified. Patients presenting with perilunate dislocations were excluded. The clinical and radiographic record for each of these patients was reviewed. Demographic information, mechanisms of injury, concomitant injuries, scaphoid fracture pattern, distal radius fracture pattern, method of treatment, and radiographic healing was recorded. Distal radius and scaphoid fractures were classified by both a board-certified hand surgeon and senior orthopaedic resident. This study was approved by the University of Iowa Hospitals Institutional Review Board.

\section{Results}

The database search yielded a total of 33 skeletally mature patients. Three patients were excluded because their wrist injury included a perilunate dislocation. An additional seven patients were excluded because they did not meet the criteria of having simultaneous, ipsilateral distal radius and scaphoid fractures. Several of these patients had distal radius fractures and scaphoid fractures in separate encounters, or a chronic scaphoid injury with an acute distal radius fracture, which lead to their erroneous inclusion. Thus, twenty-three patients were identified with simultaneous fractures of the ipsilateral scaphoid and distal radius for this 10 -year period. Our search did not yield concomitant injuries in any skeletally immature patients. During this same period, 2,999 skeletally mature patients underwent treatment of an isolated distal radius fracture and 446 skeletally mature patients underwent treatment for an isolated scaphoid fracture.

The average age of the patients was 37 years, with a range of 19 to 74 years. Only 3 patients were aged 60 years or older. Nineteen patients (83\%) were male and 4 female. Eight of the $23(35 \%)$ admitted to smoking cigarettes or other tobacco use. The mechanism was considered low energy in 4 patients who fell from standing height. In the remaining 19 patients (83\%), the injury mechanism was considered high energy and was a fall from substantial height or a highway speed motor vehicle accident. Six patients had an isolated wrist injury, the other 17 (74\%) sustained other injuries including head injuries (10), spine or pelvic fractures (6), other upper or lower extremity fractures (8), and one brachial plexus avulsion injury. All patients identified were treated surgically, addressing both the scaphoid fracture and the distal radius fracture (-Table $\mathbf{1})$.

Plain radiographs were used to determine the scaphoid fracture location and presence of displacement. Given the lack of consensus regarding the utility of scaphoid fracture classification systems, ${ }^{21}$ fractures were descriptively classified by location, noting any comminution or fracture line extension. Fractures were classified as displaced if $>1 \mathrm{~mm}$ of translation or angulation was present in any plane. The scaphoid fracture was a nondisplaced fracture in 22 patients (96\%), and a displaced fracture in 1 . The scaphoid fractures were located at the waist in 17 cases and at the junction between the waist and the proximal one-third in 4 cases. In the remaining 2 cases, the fracture was at the junction between the waist and the distal one-third, and both of these had a fracture line that extended distally toward the triscaphe joint. In all cases, the scaphoid fracture was treated via internal fixation with a headless compression screw. Twenty of the 23 screws were placed from a dorsal starting point (antegrade), and 3 from a volar starting point (retrograde) based on surgeon preference.

Plain radiographs were used to characterize and classify the distal radius fractures. Six were extra-articular and classified as Arbeitsgemeinschaft Osteosynthesefragen/Association for the Study of Internal Fixation (AO/ASIF) 23A1 in 1 case and $23 \mathrm{~A} 3$ in 5 cases. The 17 intra-articular fractures classified as AO/ASIF 23B1 in 3 cases, 23C2 in 7 cases, and 23C3 in 7 cases ( - Fig. 1). The distal radius fracture was addressed with a volar plate only in 14 cases, a volar plate supplemented by a dorsal bridge plate in 2 cases, a dorsal bridge plate only in 1 case, an external fixator and a volar plate in 1 case, an external fixator and supplemental percutaneous pins in 3 cases, and external fixator alone in 1 case, and percutaneous pins alone in 1 case. In all cases in which a bridge plate or an external fixator was used, the compression screw in the scaphoid was placed first. In all cases in which a volar plate was used, the compression screw was placed after scaphoid internal fixation (-Fig. 2). In two cases, the distal radioulnar joint (DRUJ) was unstable after distal radius internal fixation. This was treated by reducing and cross-pinning the DRUJ in 1 patient, and reducing and repairing the ulnar styloid/triangular fibrocartilage complex (TFCC) in the other patient. A triquetral avulsion fracture was present in 1 case and ulnar styloid fracture in 11 cases. No other concomitant carpal injuries were identified. Computed tomography (CT) scans were not performed preoperatively.

Three patients (13\%) presented with symptoms suggestive of median nerve compression at the time of their injury or developed it in the early postoperative period and underwent carpal tunnel release. Two patients had a delayed presentation of carpal tunnel syndrome and had carpal tunnel release greater than 6 weeks postoperatively. No patients developed surgical site infections. Patients without external fixators were rigidly immobilized postoperative in a splint or case for 6 weeks. Patients treated with bridge plates underwent bridge 
Table 1 Patient demographics and fracture characteristics

\begin{tabular}{|c|c|c|c|c|c|c|c|}
\hline Age & Sex & $\begin{array}{l}\text { Distal radius } \\
\text { classification }\end{array}$ & Scaphoid & Mechanism & $\begin{array}{l}\text { Treatment of } \\
\text { distal radius }\end{array}$ & $\begin{array}{l}\text { Treatment of } \\
\text { scaphoid }\end{array}$ & Complications \\
\hline 22 & $M$ & $23-C 2$ & $\begin{array}{l}\text { Junction of proximal } \\
1 / 3,2 / 3 \text { nondisplaced }\end{array}$ & High energy & $\begin{array}{l}\text { External fixator } \\
\text { and CRPP }\end{array}$ & Compression screw & $\begin{array}{l}\text { None, lost to } \\
\text { follow-up }\end{array}$ \\
\hline 24 & $M$ & $23-A 2$ & Waist, nondisplaced & High energy & Volar plate & Compression screw & None \\
\hline 25 & $\mathrm{M}$ & $23-A 3$ & Waist, nondisplaced & High energy & $\begin{array}{l}\text { External fixator } \\
\text { and CRPP }\end{array}$ & Compression screw & $\begin{array}{l}\text { Delayed carpal } \\
\text { tunnel release }\end{array}$ \\
\hline 32 & $\mathrm{~F}$ & $23-C 3$ & Waist, nondisplaced & High energy & $\begin{array}{l}\text { External fixator } \\
\text { and volar plate }\end{array}$ & Compression screw & None \\
\hline 20 & $M$ & $23-C 2$ & $\begin{array}{l}\text { Junction of proximal } \\
1 / 3,2 / 3 \text { nondisplaced }\end{array}$ & Low energy & Volar plate & Compression screw & None \\
\hline 19 & $\mathrm{M}$ & $23-C 3$ & Waist, nondisplaced & High energy & $\begin{array}{l}\text { External fixator } \\
\text { and CRPP }\end{array}$ & Compression screw & None \\
\hline 52 & $M$ & $23-C 2$ & $\begin{array}{l}\text { Waist with distal } \\
\text { extension, } \\
\text { nondisplaced }\end{array}$ & High energy & Volar plate & Compression screw & None \\
\hline 49 & $\mathrm{M}$ & $23-C 2$ & Waist, nondisplaced & High energy & Volar plate & Compression screw & None \\
\hline 20 & $\mathrm{M}$ & $23-C 2$ & Waist, nondisplaced & High energy & Volar plate & Compression screw & None \\
\hline 41 & $\mathrm{M}$ & 23-B1 & Waist, nondisplaced & Low energy & Volar plate & Compression screw & None \\
\hline 35 & $\mathrm{M}$ & $23-A 3$ & Waist, nondisplaced & High energy & Volar plate & Compression screw & Carpal tunnel release \\
\hline 41 & $\mathrm{M}$ & $23-C 3$ & Waist, nondisplaced & High energy & Volar plate & Compression screw & None \\
\hline 46 & $\mathrm{~F}$ & $23-A 3$ & Waist, nondisplaced & High energy & $\begin{array}{l}\text { External } \\
\text { fixator }\end{array}$ & Compression screw & None \\
\hline 31 & $\mathrm{M}$ & $23-C 3$ & $\begin{array}{l}\text { Junction of proximal } \\
1 / 3,2 / 3 \text { nondisplaced }\end{array}$ & High energy & CRPP & Compression screw & $\begin{array}{l}\text { Scaphoid nonunion } \\
\text { and AVN }\end{array}$ \\
\hline 19 & $\mathrm{~F}$ & $23-A 3$ & $\begin{array}{l}\text { Junction of proximal } \\
1 / 3,2 / 3 \text { nondisplaced }\end{array}$ & High energy & Volar plate & Compression screw & None \\
\hline 46 & $\mathrm{M}$ & 23-B1 & Waist, nondisplaced & High energy & Volar plate & Compression screw & None \\
\hline 74 & $\mathrm{M}$ & $23-C 2$ & Distal $1 / 3$, nondisplaced & High energy & Volar plate & Compression screw & $\begin{array}{l}\text { None, lost to } \\
\text { follow-up }\end{array}$ \\
\hline 60 & $\mathrm{M}$ & $23-C 3$ & Waist, nondisplaced & High energy & $\begin{array}{l}\text { Bridge plate } \\
\text { and volar } \\
\text { plate }\end{array}$ & Compression screw & $\begin{array}{l}\text { Carpal tunnel release } \\
\text { and bridge plate } \\
\text { removal }\end{array}$ \\
\hline 66 & $\mathrm{~F}$ & $23-\mathrm{C3}$ & Waist, Displaced & Low energy & $\begin{array}{l}\text { Bridge plate } \\
\text { and volar } \\
\text { plate }\end{array}$ & Compression screw & $\begin{array}{l}\text { Immediate carpal } \\
\text { tunnel release and } \\
\text { bridge plate removal }\end{array}$ \\
\hline 40 & $\mathrm{M}$ & $23-\mathrm{C3}$ & Waist, nondisplaced & High energy & Bridge plate & Compression screw & $\begin{array}{l}\text { Delayed carpal } \\
\text { tunnel release at time } \\
\text { of bridge plate } \\
\text { removal }\end{array}$ \\
\hline 33 & M & $23-C 2$ & Waist, nondisplaced & Low energy & Volar plate & Compression screw & None \\
\hline 28 & $\mathrm{M}$ & $23-\mathrm{A} 1$ & Waist, nondisplaced & High energy & Volar plate & Compression screw & $\begin{array}{l}\text { None, lost to } \\
\text { follow-up }\end{array}$ \\
\hline 34 & $\mathrm{M}$ & 23-B1 & Waist, nondisplaced & High energy & Volar plate & Compression screw & None \\
\hline
\end{tabular}

Abbreviations: AVN, avascular necrosis; CRPP, closed reduction and percutaneous pin; F, female; M, male.

plate removal at an average of 81 days (range: 79-85). External fixators were removed at an average of 44 days (range: 38-52).

Patients were followed to radiographic union in 20 cases. Average follow-up was 19.76 weeks, with a range from 6 to 40 weeks. Three patients were lost to follow-up. Two of these patients were visiting at the time of their injury and returned to their home state after the first postoperative visit. Plain radiographs were used to assess fracture healing postoperatively. If plain radiographs were concerning for nonunion, a CT scan was ordered. Nineteen of the 20 patients (95\%) had radiographic union of the scaphoid during their follow-up. In one patient, the radiographs did not indicate union, so a CT scan was obtained which confirmed a nonunion of the fracture and avascular changes proximal to the fracture line. All 20 of the distal radius fractures healed radiographically (-Fig. 3). Standard posteroanterior and lateral radiographs were used to evaluate the alignment of the healed distal radius. Anatomic 

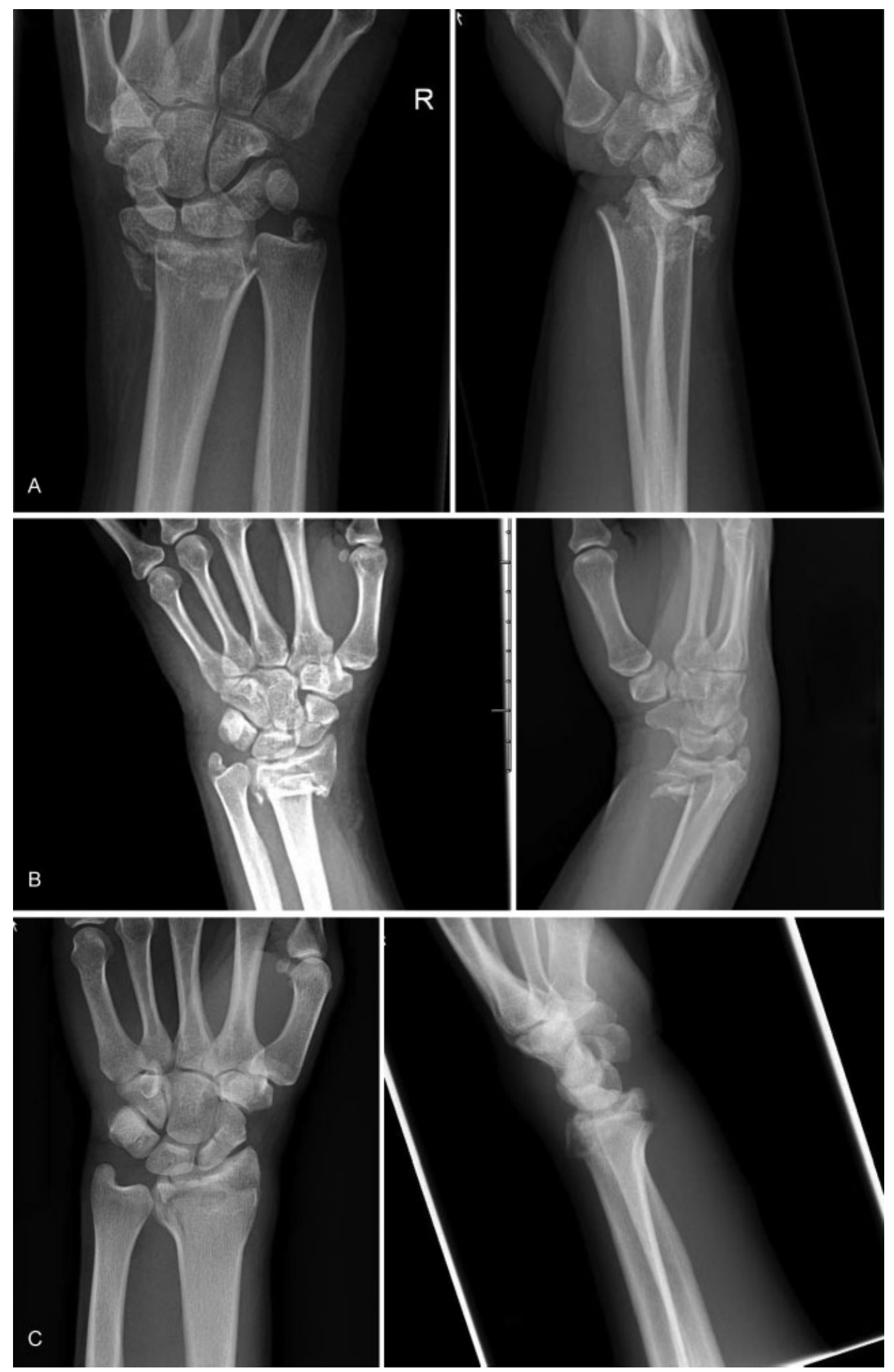

Fig. 1 Injury radiographs demonstrating variety of distal radius fracture patterns. (A) AO 23C3 fracture with dorsal angulation. (B) AO $23 C 3$ fracture with volar displacement. (C) AO $23 \mathrm{C} 2$ fracture with minimal displacement or angulation. 

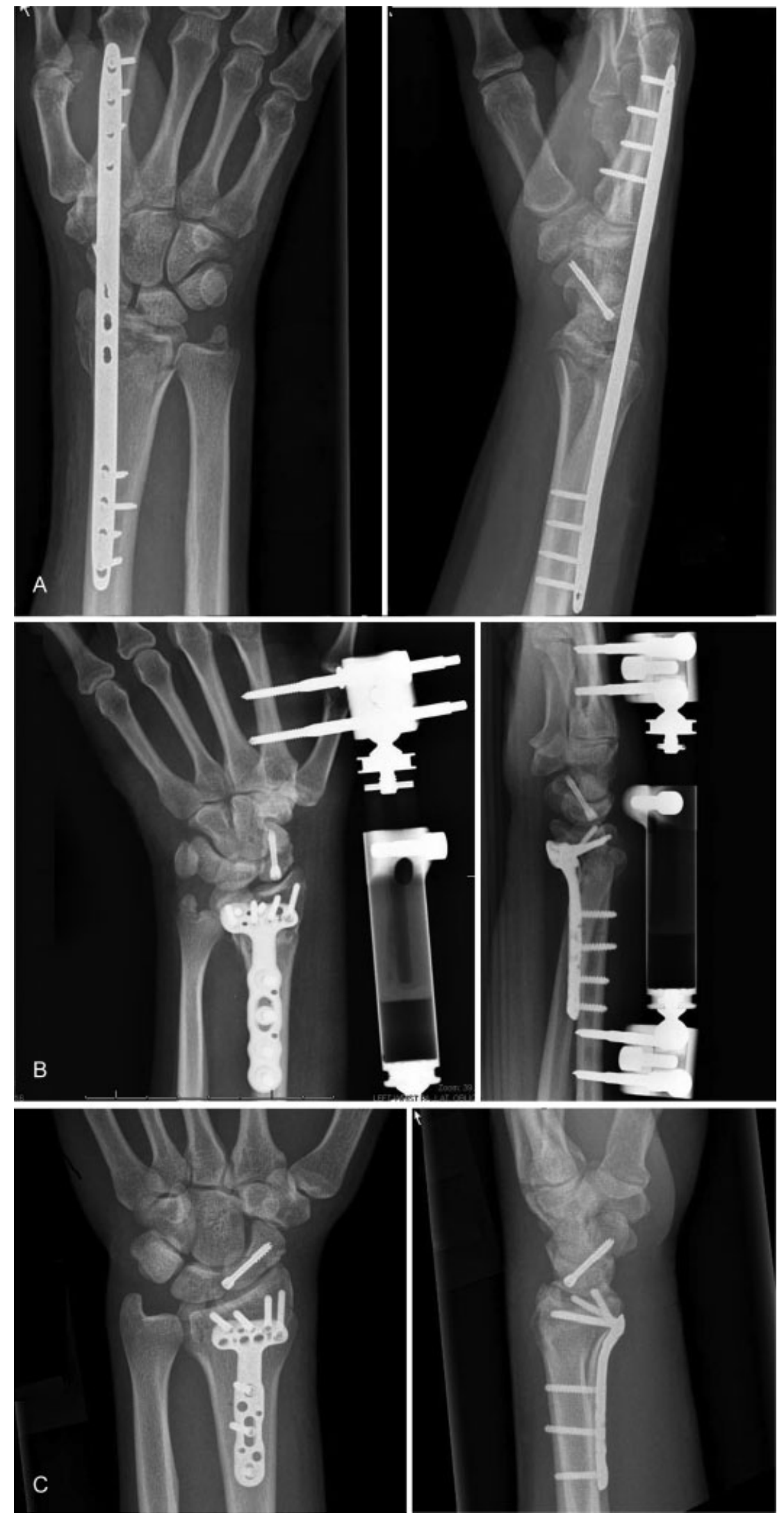

Fig. 2 Early postoperative radiographs of cases shown in - Fig. 1. (A) Distraction resulted in a satisfactory reduction of the distal radius fracture, so a spanning bridge plate alone was used. (B) A volar plate was used to reduce and internally fix the distal radius. This was supplemented with external fixation. (C) A volar plate alone for internal fixation. 

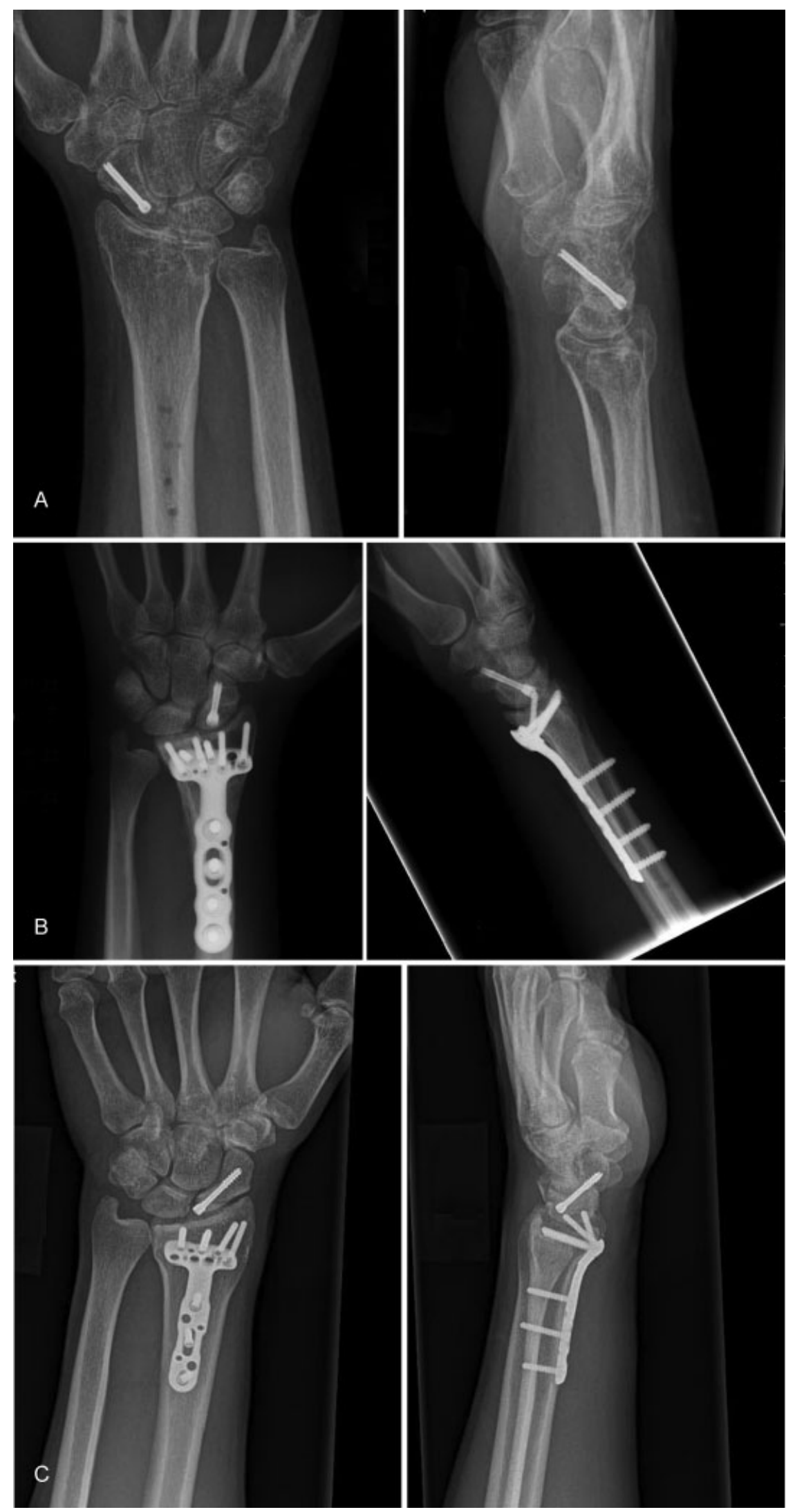

Fig. 3 Final postoperative radiographs of cases shown in - Figs. 1 and 2. (A) Bridge plate has been removed, distal radius judged to have healed anatomically. (B) External fixator has been removed, distal radius judged to have healed anatomically. (C) Distal radius healed anatomically. 
alignment was defined by no articular step-offs $>2 \mathrm{~mm}$, volar tilt of $11 \pm 5^{\circ}$, and radial inclination of $22 \pm 3^{\circ} .^{22}$ Sixteen of the $20(80 \%)$ radius fractures were judged to have healed in anatomic alignment. One fracture healed with an articular step off of $>2 \mathrm{~mm}$. Three fractures healed with loss of radial inclination.

\section{Discussion}

We present a series of patients who sustained simultaneous fractures of the ipsilateral scaphoid and distal radius and presented to single institution over a 10 -year period. A rare injury, this represented less than $0.76 \%$ of skeletally mature patients with isolated distal radius fractures and $4.9 \%$ of skeletally mature patients with isolated scaphoid fractures treated at our institution during this time period.

Most of the injury mechanisms in this series were high energy, with only four patients sustaining fractures from falls from standing height. In 19 of the 23 cases (83\%), the distal radius fracture had significant displacement and/or comminution, classified as AO/ASIF A3 (5), C2 (7), and C3 (7). Seventeen of 23 (74\%) patients had other injuries requiring intervention. Previous authors also noted high-energy mechanisms of injury in their series of concurrent scaphoid and distal radius fractures. ${ }^{6,8,9}$ In contrast, Vukov et al suggest a low-energy mechanism of injury, stating that "minimal or slight displacement of fracture of the radius is the most significant feature of this entity." In their series of simultaneous scaphoid and distal radius fractures, which is the largest, over half of the 26 patients were female, "mainly in the fifth decade of life." 10 The demographics of this series are quite different, with $83 \%$ male patients, $87 \%$ of patients under age 60 , and $83 \%$ of the distal radius fractures having significant displacement and/or comminution.

The scaphoid fractures in this series varied little. All scaphoids fractured at the waist, although there was variation in the exact location. Four of 23 occurred at the junction of the proximal and middle third, and 2 of the 23 occurred at the junction of the middle and distal third. Twenty-two of 23 (96\%) scaphoid fractures were nondisplaced. The only displaced scaphoid fracture occurred in an elderly woman with marked osteopenia. In the series by Vukov et al, all 26 scaphoid fractures were nondisplaced, transverse waist fractures. Furthermore, they noted that 19 of the 26 scaphoid fractures were at the junction of the proximal and middle third of the scaphoid. ${ }^{10}$ Oskam et al presented 23 cases, and all scaphoid fractures were described as nondisplaced and involving the waist or distal third. ${ }^{4}$ In contrast to this uniformity in scaphoid fracture patterns, in their review of all carpal fractures concurrent with distal radius fractures Komura et al identified fractures of the scaphoid waist ( 2 cases), dorsal ridge (2 cases), "distal scaphoid" (1 case), and "proximal scaphoid" (3 cases). Komura et al also found that CT scans were more sensitive than plain radiographs at detecting carpal injuries concurrent with distal radius fractures. ${ }^{3}$ In this series, CT scans were not routinely performed before surgical intervention.

Unlike the scaphoid, the pattern of distal radius fractures varied widely in this series. Six were extra-articular and varied in degree of displacement. Three were simple articular fractures. The remaining 14 were intra-articular with displacement and/or comminution. Previous reports also indicate variability in the distal radius fracture, ${ }^{4,9,10}$ but the lack of uniformity in the description of the fracture makes comparisons difficult. Only Komura et al characterized fractures using the AO/ASIF system. ${ }^{3}$ Hove included a greenstick fracture of the radius and a trans-styloid, transscaphoid perilunate dislocation in his series of 12 patients with simultaneous fractures. ${ }^{1}$ Our database search did not identify any simultaneous fractures in skeletally immature patients, and we excluded perilunate dislocations.

The combination of a scaphoid and distal radius fracture presents a conflict when applying principles of fixation. Scaphoid fracture fixation is generally compression, while distal radius fracture reduction usually requires distraction. Proubasta and Lluch used external fixation across the carpus to treat two patients with displaced distal radius fractures and nondisplaced scaphoid fractures, with no internal fixation of the scaphoid but recommending an additional pin in the thumb metacarpal to better stabilize the scaphoid. ${ }^{13}$ Richards et al recommended compression screw fixation of the scaphoid prior to external fixation. ${ }^{5}$ Slade et al recommended reduction and provisional pinning of the scaphoid before reduction of the radius. ${ }^{11}$ While all scaphoid fractures in this series received a headless compression screw, the treatment methods applied to the radial side varied and were determined by the treating physician. A volar locking plate was used on the radius in 16 (70\%) cases, and in 2 of these cases a dorsal bridge plate was used to supplement fixation. In all of these cases, scaphoid reduction and fixation was performed after volar plating of the distal radius. External fixation was used in five cases, but never after 2010. In these cases, traction via the external fixator was not applied until the scaphoid compression screw was placed. In the remaining two cases, the distal radius fracture was addressed once with percutaneous pins only and once with a bridge plate only.

With the exception of Vukov et al who treated all patients with 8 weeks of casting, ${ }^{10}$ treatment methods also varied in the previous reports and likely were determined by the preference of the treating physician and contemporary trends. One unexpected finding was that all simultaneous fractures seen at this institution since 2007 were treated surgically. This is likely due to the high-energy nature of the fracture, the presence of other injuries, and the general trend toward surgical intervention for distal radius and scaphoid fractures.

A remarkable finding in this and in other reports of simultaneous fractures is the high healing rate of the scaphoid. Of the 20 patients followed to radiographic union, 19 scaphoid fractures healed (95\%). The one nonunion occurred in the patient with an ipsilateral brachial plexus injury with nerve root avulsions at C7-T1. This patient elected no additional treatment, and has been lost to follow-up. All seven patients treated with transcarpal distraction by external fixators or bridge plates healed their scaphoid fractures. One of the eight patients who use tobacco at the time of injury was lost to follow-up, but the remaining seven tobacco users went on to radiographic union. In the 104 patients reported on in previous 


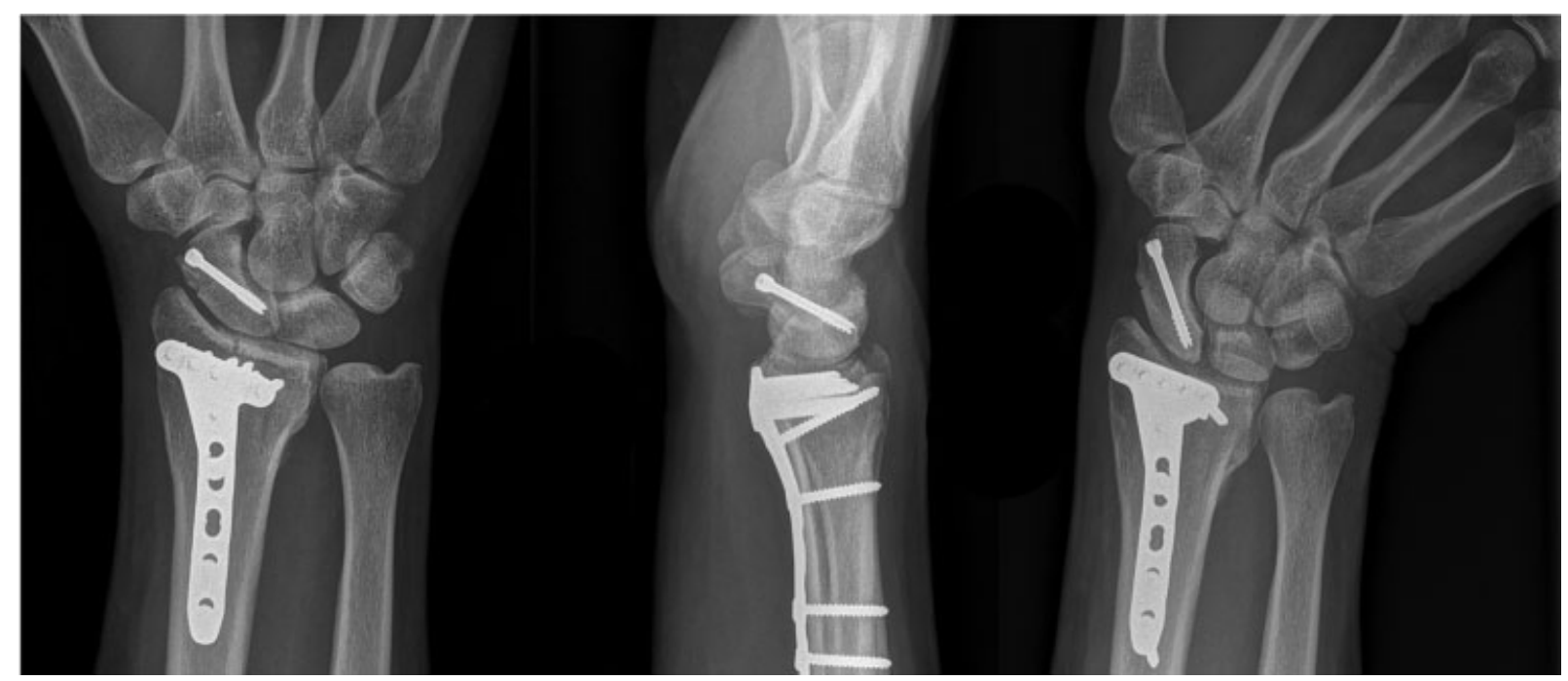

Fig. 4 Radiographs at 43 days postoperatively, with the scaphoid appearing to unite. We considered this a healed scaphoid, despite losing the patient to follow-up.

series available for full review, 102 scaphoids healed, ${ }^{1-11}$ and 1 scaphoid's healing status was "unknown." In this and in all other series published since 1988 , healing was determined by plain X-ray. We judged the scaphoid to be healed if bridging bone was appreciated $>50$ across the fracture, no cystic changes or sclerosis was present at the fracture site, and no hardware loosening was visible. This is a potential weakness of these studies, since $\mathrm{CT}$ is considered the most reliable way to characterize the healing status of a scaphoid fracture, ${ }^{23-27}$ and it is not possible to definitively state that a scaphoid fracture is healed at 6 weeks without advanced imaging. However, it is not routine to obtain a CT scan when plain radiographs strongly indicate healing (-Fig. 4). Advanced imaging is typically obtained when plain radiographs are inconclusive. As noted above, this situation arose in one patient in this series, and the $\mathrm{CT}$ scan confirmed the presence of nonunion and suggested avascular necrosis.

All 20 distal radius fractures available for follow-up united. One simple articular fracture (AO 23B1) healed with an intra-articular step-off $>2 \mathrm{~mm}$ and had been treated with a volar plate. Three healed with loss of radial inclination and had been treated with a volar plate (AO 23C2), a volar plate with supplemental dorsal bridge plate (AO 23C3), and an external fixator alone (AO 23A3).

This retrospective study has several weaknesses. Database searches using CPT and ICD codes will not identify patients who were coded incorrectly. Also, our search method only identified patients coded simultaneously for scaphoid and distal radius fractures. A patient who sustained the fractures simultaneously but in whom the fractures were not recognized simultaneously (e.g., the scaphoid fracture was recognized during follow-up for the distal radius fracture) would not have been identified. In this series, scaphoid fracture location and the presence of displacement was determined by plain radiographs. CT was not used preoperatively to better characterize the scaphoid fracture. Previous reports indicate that displacement of scaphoid fractures is best determined by CT scans ${ }^{28,29}$ or even by arthroscopy. ${ }^{24}$ Finally, limited conclusions can be drawn from clinical studies in which the treatment methods were not uniform. Since this series lacks clinical outcomes data and longer term clinical and radiographic follow-up, it cannot be used to determine which treatment methods are superior.

Despite these shortcomings, we feel this report adds to the limited volume of knowledge regarding simultaneous fractures of the ipsilateral scaphoid and distal radius. From this series we make the following conclusions: (1) the injury mechanism is usually of high energy; (2) the scaphoid is nearly always fractured at the waist and is nondisplaced; (3) the distal radius fracture pattern varies widely; and (4) the treatment method at our institution typically involves internal fixation of the scaphoid and volar plating of the distal radius, reflecting contemporary trends in fracture management.

Note

This study was approved by the Institutional Review Board.

\section{Funding}

None.

\section{Conflict of Interest}

None.

\section{References}

1 Hove LM. Simultaneous scaphoid and distal radial fractures. J Hand Surg [Br] 1994;19(03):384-388

2 Jenkins NH, Jones DG. Simultaneous Colles' and scaphoid fractures: treatment by combined internal and external fixation. Am J Emerg Med 1986;4(03):229-230

3 Komura S, Yokoi T, Nonomura H, Tanahashi H, Satake T, Watanabe $\mathrm{N}$. Incidence and characteristics of carpal fractures occurring concurrently with distal radius fractures. J Hand Surg Am 2012; 37(03):469-476

4 Oskam J, De Graaf JS, Klasen HJ. Fractures of the distal radius and scaphoid. J Hand Surg [Br] 1996;21(06):772-774 
5 Richards RR, Ghose T, McBroom RJ. Ipsilateral fractures of the distal radius and scaphoid treated by Herbert screw and external skeletal fixation. A report of two cases. Clin Orthop Relat Res 1992;(282):219-221

6 Smith JT, Keeve JP, Bertin KC, Mann RJ. Simultaneous fractures of the distal radius and scaphoid. J Trauma 1988;28(05):676-679

7 Stother IG. A report of 3 cases of simultaneous Colles' and scaphoid fractures. Injury 1976;7(03):185-188

8 Tountas AA, Waddell JP. Simultaneous fractures of the distal radius and scaphoid. J Orthop Trauma 1987;1(04):312-317

9 Trumble TE, Benirschke SK, Vedder NB. Ipsilateral fractures of the scaphoid and radius. J Hand Surg Am 1993;18(01):8-14

10 Vukov V, Ristić K, Stevanović M, Bumbasirević M. Simultaneous fractures of the distal end of the radius and the scaphoid bone. J Orthop Trauma 1988;2(02):120-123

11 Slade JF III, Taksali S, Safanda J. Combined fractures of the scaphoid and distal radius: a revised treatment rationale using percutaneous and arthroscopic techniques. Hand Clin 2005;21 (03):427-441

12 Chang CH, Tsai YS, Sun JS, Hou SM. Ipsilateral distal radius and scaphoid fractures. J Formos Med Assoc 2000;99(09):733-737

13 Proubasta IR, Lluch AL. Concomitant fractures of the scaphoid and the distal end of the radius: treatment by external fixation. A report of two cases. J Bone Joint Surg Am 1991;73(06):938-940

14 Orbay JL, Fernandez DL. Volar fixation for dorsally displaced fractures of the distal radius: a preliminary report. J Hand Surg Am 2002;27(02):205-215

15 McQueen MM, Gelbke MK, Wakefield A, Will EM, Gaebler C. Percutaneous screw fixation versus conservative treatment for fractures of the waist of the scaphoid: a prospective randomised study. J Bone Joint Surg Br 2008;90(01):66-71

16 Bond CD, Shin AY, McBride MT, Dao KD. Percutaneous screw fixation or cast immobilization for nondisplaced scaphoid fractures. J Bone Joint Surg Am 2001;83-A(04):483-488

17 Saedén B, Törnkvist H, Ponzer S, Höglund M. Fracture of the carpal scaphoid. A prospective, randomised 12-year follow-up comparing operative and conservative treatment. J Bone Joint Surg $\mathrm{Br}$ 2001;83(02):230-234

18 Buijze GA, Doornberg JN, Ham JS, Ring D, Bhandari M, Poolman RW. Surgical compared with conservative treatment for acute nondisplaced or minimally displaced scaphoid fractures: a sys- tematic review and meta-analysis of randomized controlled trials. J Bone Joint Surg Am 2010;92(06):1534-1544

19 Dias JJ, Wildin CJ, Bhowal B, Thompson JR. Should acute scaphoid fractures be fixed? A randomized controlled trial. J Bone Joint Surg Am 2005;87(10):2160-2168

20 Vinnars B, Pietreanu M, Bodestedt A, Ekenstam FA, Gerdin B. Nonoperative compared with operative treatment of acute scaphoid fractures. A randomized clinical trial. J Bone Joint Surg Am 2008;90(06):1176-1185

21 Ten Berg PW, Drijkoningen T, Strackee SD, Buijze GA. Classifications of acute scaphoid fractures: a systematic literature review. J Wrist Surg 2016;5(02):152-159

22 Mignemi ME, Byram IR, Wolfe CC, et al. Radiographic outcomes of volar locked plating for distal radius fractures. J Hand Surg Am 2013;38(01):40-48

23 Dias JJ, Taylor M, Thompson J, Brenkel IJ, Gregg PJ. Radiographic signs of union of scaphoid fractures. An analysis of inter-observer agreement and reproducibility. J Bone Joint Surg Br 1988;70(02): 299-301

24 Buijze GA, Jørgsholm P, Thomsen NO, Bjorkman A, Besjakov J, Ring D. Diagnostic performance of radiographs and computed tomography for displacement and instability of acute scaphoid waist fractures. J Bone Joint Surg Am 2012;94(21):1967-1974

25 Grewal R, Frakash U, Osman S, McMurtry RY. A quantitative definition of scaphoid union: determining the inter-rater reliability of two techniques. J Orthop Surg 2013;8:28

26 Grewal R, Suh N, Macdermid JC. Use of computed tomography to predict union and time to union in acute scaphoid fractures treated nonoperatively. J Hand Surg Am 2013;38(05):872-877

27 Smith ML, Bain GI, Chabrel N, Turner P, Carter C, Field J. Using computed tomography to assist with diagnosis of avascular necrosis complicating chronic scaphoid nonunion. J Hand Surg Am 2009;34(06):1037-1043

28 Lozano-Calderón S, Blazar P, Zurakowski D, Lee SG, Ring D. Diagnosis of scaphoid fracture displacement with radiography and computed tomography. J Bone Joint Surg Am 2006;88(12): 2695-2703

29 ten Berg PW, Dobbe JG, Strackee SD, Streekstra GJ. Quantifying scaphoid malalignment based upon height-to-length ratios obtained by 3-dimensional computed tomography. J Hand Surg Am 2015;40(01):67-73 